Especial: Profesores de Estudios Generales Investigan

II Sección: Docentes e investigación: tarea continua en Estudios Generales

\title{
La Revolución bolivariana: humanismo y contracultura
}

\author{
Asdrúbal Marín Murillo \\ Universidad de Costa Rica, Costa Rica \\ asmarinm@gmail.com \\ https://orcid.org/0000-0003-2717-1224
}

Recibido: 31 de noviembre de 2019

Aceptado: 31 de enero de 2020

Resumen: La Revolución bolivariana es un proceso político, económico e ideológico que se ubica dentro del espectro denominado socialismo del siglo XXI. $\mathrm{Su}$ proyecto revolucionario es una propuesta humanista, cultural y contrahegemónica que examina y confronta los valores tradicionales de una Venezuela excluyente y represora, fundada en los principios del gran capital y de la acumulación desmedida. La Revolución bolivariana no es solo un planteamiento ideológico y político económico, es a la vez un movimiento contracultural y antisistema que busca una transformación total de los principios y fines de una cultura arraigada y sostenida por el pensamiento de los grupos tradicionales del gran capital venezolano.

Palabras Claves: Humanismo, Ideología, Revolución, Contracultura, política, Capitalismo, Socialismo.

\section{The Bolivarian Revolution: Humanism and counterculture}

Abstract: The Bolivarian Revolution is a political, economic and ideological process that is located within the movement called socialism of the XXI century. Its revolutionary project is a humanistic, cultural and counter-hegemonic proposal that analyses and confronts the traditional values of an excluding and repressive Venezuela founded on the principles of big capital and excessive accumulation. The Bolivarian Revolution is not just an ideological and political economic

\section{(c) (i) (2) (2)}

La Revista Estudios es editada por la Universidad de Costa Rica y se distribuye bajo una Licencia Creative Commons Atribución-NoComercial-CompartirIgual 3.0 Costa Rica. Para más información envíe un mensaje a 


\section{Especial: Profesores de Estudios Generales Investigan}

approach, at the same time, it is a countercultural, anti-system and humanist movement that seeks a total transformation of the principles and goals of a culture rooted and sustained by the thinking of the traditional groups who belong to the big Venezuelan capital.

Keywords: Humanism, ideology, revolution, counterculture, politics, capitalism, socialism.

\section{Introducción}

A lo largo del desarrollo y evolución de la humanidad, en los campos político, social y cultural se han dado movimientos que han marcado un antes y un después en el transcurso de la historia. La mayor parte de esos movimientos se han caracterizado por contribuir a la elaboración de concepciones de mundo y de ser humano distintas a las prevalecientes en ese momento en la sociedad; movimientos que buscan nuevas formas de ver y entender el mundo. Sus aportes han sido tan significativos en todos los niveles que incluso han llevado a cabo grandes transformaciones tanto en lo social como en lo cultural. Sus aportes van desde grandes acontecimientos hasta pequeñas innovaciones. Ejemplos de esos movimientos tenemos muchos y en todos los campos. Sin entrar en juicios o valoraciones de tipo político, moral o religioso, podemos mencionar el cristianismo, la Reforma protestante, el islamismo, la Revolución francesa, la Revolución rusa, la Revolución cultural china, los movimientos revolucionarios y políticos en América Latina. Se han dado otros movimientos que, a pesar de no haber tenido un impacto universal, sí han dejado un fuerte legado a la humanidad; una gran mayoría de ellos en nuestro continente latinoamericano. Podríamos mencionar los movimientos indigenistas, la Revolución cubana, la Revolución sandinista, la Revolución mexicana, el gobierno de Salvador Allende, Tlatelolco en México, Córdoba en Argentina; bien podríamos seguir aquí exponiendo ejemplos como esos y como muchos otros, pues también los ha habido en el campo de la música, el arte, la literatura, la poesía, la pintura o la filosofía. No vamos a entrar aquí a analizar sus aportes, sus manifestaciones, sus peculiaridades, su duración o

La Revista Estudios es editada por la Universidad de Costa Rica y se distribuye bajo una Licencia Creative Commons Atribución-NoComercial-CompartirIgual 3.0 Costa Rica. Para más información envíe un mensaje a revistaestudios.eeg@ucr.ac.cr. 


\section{Especial: Profesores de Estudios Generales Investigan}

impacto en la sociedad de su tiempo; nos interesa más bien otro elemento, el cual lo vamos a sintetizar en una pregunta: ¿Qué elementos tienen en común y que interés articula a cada uno de esos movimientos? Independientemente de los intereses, las características y otras particularidades propias de cada uno de ellos, mantienen en común dos cosas que los identifica en sus luchas y manifestaciones: enfrentan un orden político, económico, social y cultural establecido, y expresan el deseo de construir una alternativa nueva y diferente a ese orden hegemónico. Construir su propio espacio inclusivo, justo, participativo, que les pudiera permitir expresar libremente su propia forma de ser, de pensar y de sentir; aspectos que les eran negados por la cultura oficial dominante.

Nos interesa en este artículo analizar el papel de un movimiento muy reciente en América Latina y que se enmarca dentro de lo que se denomina socialismo del siglo XXI; ese movimiento está representado por la Revolución bolivariana en Venezuela. Consideramos que ella representa un movimiento humanista, de carácter socialista, identitario y de orden contracultural; es decir, es una nueva tendencia vinculada a sectores sociales excluidos y relegados por una cultura dominante, elitista, que representa a grupos de poder que se han autodenominado por años como la cultura oficial. La Revolución bolivariana es un enclave contracultural de carácter popular, que lucha contra una cultura hegemónica de orden político económico.

La Revolución bolivariana es de carácter contracultural, porque se trata de un movimiento contestatario alternativo que surge al interior de una cultura oficial dominante. El mismo se articula a partir de concepciones e ideales que se distancian de esa visión hegemónica oficial que entiende, interpreta y explica la sociedad según sus propios intereses capitalistas. Hacia lo anterior nos apunta Britto García (1994) cuando afirma que una contracultura "comienza cuando ante la cultura dominante surge una subcultura que diverge de ella. La batalla se traba

\section{(a) $(\mathbb{Q} \Theta$}

La Revista Estudios es editada por la Universidad de Costa Rica y se distribuye bajo una Licencia Creative Commons Atribución-NoComercial-CompartirIgual 3.0 Costa Rica. Para más información envíe un mensaje a 


\section{Especial: Profesores de Estudios Generales Investigan}

cuando esta subcultura contradice abiertamente a la cultura dominante: desde entonces se convierte en contracultura" (p.16).

Las contraculturas enfrentan al poder dominante en una gran diversidad de formas y múltiples aspectos, lo hacen mediante provocaciones, transgresiones, irreverencias, exabruptos, rompimiento de patrones, rebeldía, lenguajes provocativos, confrontación a la ratio oficial y dominante. Son propuestas que responden al deseo de liberación de un sector de la sociedad que busca emanciparse de la barbarie oficial del sistema dominante.

Reafirmando lo anterior, respecto al conflicto que se genera en una sociedad donde sectores de la población expresan su malestar enfrentando a la cultura dominante, el mismo Britto García (1994) nos dice: "Cuando una subcultura llega a un grado de conflicto irreconciliable con la cultura dominante, se produce una contracultura: una batalla entre modelos, una guerra entre concepciones del mundo, que no es más que la expresión de la discordia entre grupos que ya no se encuentran integrados ni protegidos dentro del conjunto del cuerpo social" (p.18). Este enfrentamiento entre formas de entender el mundo o entre modelos políticos, económicos y sociales que se da hoy en día en la República Bolivariana de Venezuela es un desacuerdo entre sectores sociales marginados, excluidos y desplazados, una subcultura, que busca rehacer su humanidad recuperando lo que otro sector, con capacidad económica y poder político, ha asumido como suyo y no lo quiere comunizar con el resto de la población. Es una contracultura que considera que su proyecto alternativo es viable, es ético, es posible y representa los intereses de las mayorías.

\section{(c) (1) (2)}

La Revista Estudios es editada por la Universidad de Costa Rica y se distribuye bajo una Licencia Creative Commons Atribución-NoComercial-CompartirIgual 3.0 Costa Rica. Para más información envíe un mensaje a 


\section{Especial: Profesores de Estudios Generales Investigan}

\section{La Revolución bolivariana: socialismo, contracultura y humanismo}

Ubicados ya, aunque de una manera muy breve y general, respecto de lo que entendemos por contracultura, vamos ahora a intentar un acercamiento con la Revolución bolivariana. El proceso revolucionario venezolano irrumpió abruptamente en el clima político latinoamericano. Cuando en noviembre de 1989 cayó el Muro de Berlín y se inició el colapso de la URSS, pocos años después aparece en América del Sur el proceso revolucionario venezolano que con su Revolución bolivariana y su propuesta de socialismo del siglo XXI contradice y confronta la cultura política oficial que durante muchas décadas había impuesto su dominación de clase y su hegemonía económica. Como proyecto político específico dentro de lo que se conoce como socialismo del siglo XXI, si bien es cierto que responde al contexto histórico social particular de la República Bolivariana de Venezuela, posee y expresa rasgos propios del pensamiento marxista tradicional: manifiesta un accionar liberador, humanista, antiimperialista, anticapitalista, inclusivo, independentista, socialista y emancipador. Estos rasgos, a la vez, se conjuntan y manifiestan como elementos partícipes e inherentes a las sensibilidades contraculturales, cuyo valor sociopolítico es retar y desafiar el poder dominante. Los hippies, los punks, los góticos, el rock, entre muchas otras corrientes contraculturales, tuvieron como característica principal el enfrentamiento contra la cultura oficial; sus manifestaciones siempre convocaban polémicas, conflictos desafíos y amenazas al sistema.

Estas características propias de los movimientos de contracultura están presentes en la Revolución bolivariana y en quien fuera su principal líder y máximo dirigente, Hugo Chávez. Desafiante y provocador, se enfrentó a las clases dominantes venezolanas y al imperio norteamericano; pero no solo su máximo líder, el comandante Chávez, expresó esa actitud propia de estas corrientes; la plataforma programática de la Revolución bolivariana en sí misma es desafiante,

La Revista Estudios es editada por la Universidad de Costa Rica y se distribuye bajo una Licencia Creative Commons Atribución-NoComercial-CompartirIgual 3.0 Costa Rica. Para más información envíe un mensaje a 


\section{Especial: Profesores de Estudios Generales Investigan}

amenazadora y confrontativa. La presencia del proyecto bolivariano en la sociedad venezolana ha desatado una respuesta violenta y brutal por parte de las clases oligarcas y otros grupos de poder tradicionales. La propuesta de una plataforma política y de una nueva sociedad sustentada en valores opuestos a los de la cultura dominante expresa el carácter mismo de un movimiento contracultural. El proyecto bolivariano es una alternativa distinta, innovadora y antisistema; es la búsqueda de romper con la mentalidad hegemónica del poder oficial, su forma y concepción de la vida, de la sociedad y de la persona. El nombre mismo de socialismo del siglo $X X I$ es ya toda una innovación teórico-política, se distancia en cierta forma de los socialismos que le anteceden; no solo rompe con la mentalidad de la oligarquía tradicional y su proyecto excluyente de sociedad, sino que implica también un distanciamiento del socialismo tradicional llevado a la práctica por la extinta Unión Soviética y los países del Este. Contextualiza su proyecto revolucionario según el contexto histórico social y real en el cual se llevará a cabo, esto lo convierte en un socialismo diferente e innovador; incluso marca una distancia respecto al mismo proceso revolucionario cubano. Su estrategia política está fundada en "la construcción de poder desde abajo y desde adentro" (Dieterich, 2003, p.9).

El surgimiento de la Revolución bolivariana en el contexto social, económico, político e ideológico latinoamericano está ligado a una serie de elementos históricos, culturales, sociales y políticos que forman parte de la historia del pueblo venezolano y que se pueden hacer extensivos a la realidad política latinoamericana. Fue Venezuela gobernada por una clase política oligárquica, asentada en el latifundio, la explotación petrolera y los yacimientos de gas. Esta forma de gobernar desde arriba y para los de arriba, acabó por consolidar una clase social y económica dueña de la riqueza del país que, mancomunada al sector político, se convirtieron en amos y señores del poder. La relación con los sectores populares fue de explotación, represión, exclusión y abandono. Sus

\section{(c) (i) (-)}

La Revista Estudios es editada por la Universidad de Costa Rica y se distribuye bajo una Licencia Creative Commons Atribución-NoComercial-CompartirIgual 3.0 Costa Rica. Para más información envíe un mensaje a 


\section{Especial: Profesores de Estudios Generales Investigan}

tácticas de acumulación y lucro estuvieron por encima de los intereses generales de la población. Esta actitud insensible, deshumanizada y poco solidaria acumuló descontento entre los sectores sociales, sobre todo en aquellos más pobres de la sociedad.

En la base de una sociedad elitista, opulenta y consumista, se asentó otra clase social totalmente miserable y sin acceso a las mínimas condiciones de vida. Esa clase social excluida, paupérrima y precarizada se consolidó como una subcultura al interior de ese orden opulento y jerarquizado, desarrollando una visión de mundo, de sociedad y de ser humano distinto al de la cultura oficial. El poder hegemónico y represor se logró mantener gracias a la imposición de sus propios valores culturales. Esta cultura y pensamiento oficial lo explica muy bien Harnecker (2001) cuando afirma que

el poder enemigo no solo es represivo sino [...] también constructor, moldeador, disciplinante. Si el poder de las clases dominantes solo actuase como censura, exclusión, como instalación de obstáculos o represión, sería más frágil. Si es más fuerte es porque además de evitar lo que no quiere es capaz de construir lo que quiere, de moldear conductas, de producir saberes, racionalidades, consciencias, de forjar una forma de ver el mundo y de verlo a él mismo. (p.1)

Una sociedad bajo las condiciones descritas por Harnecker (2001) gesta y reproduce sectores sociales excluidos que, descontentos ante una realidad tan deshumanizada y desesperanzadora, a la vez que confronta, rivaliza y provoca el orden establecido, busca los medios alternativos necesarios para la construcción de una sociedad más humana, inclusiva, segura y gestora de oportunidades para todos; de esta forma se fomentan en la sociedad los movimientos contraculturales que convocan y buscan el cambio. Ante una sociedad que les niega todo y los envilece, la propuesta es una acción liberadora que los emancipa del

\section{(c) (i) (2) (2)}

La Revista Estudios es editada por la Universidad de Costa Rica y se distribuye bajo una Licencia Creative Commons Atribución-NoComercial-CompartirIgual 3.0 Costa Rica. Para más información envíe un mensaje a 
Especial: Profesores de Estudios Generales Investigan

sometimiento. Ante condiciones históricas como las apuntadas arriba, Gallardo (2006) nos dice que "lo popular-social y cultural aparecía sobredeterminado por la necesidad y urgencia de su liberación. Esa liberación prometía abrir mundos personales, sociales y nacionales originales" (pp.135-136).

Esta urgencia de su liberación, citada por Gallardo (2006), es lo que hace posible, urgente y necesario los movimientos de confrontación en la sociedad; es ahí, precisamente, donde se presenta el surgimiento de las nuevas alternativas desafiantes al sistema. La Revolución bolivariana la incluimos dentro de estas nuevas alternativas contraculturales que se gestan para combatir el poder tradicional. Su nacimiento y consolidación en la sociedad venezolana es la respuesta a décadas de exclusión y olvido que provocaron esas prácticas políticas y económicas tradicionales. Ante una cultura represiva y hegemónica, ante una élite aburguesada y oligárquica que considera que su visión y concepción del mundo, de la sociedad y de la persona es la única cultura posible que debe ser asumida como propia por todos sus ciudadanos, emergen nuevas formas, nuevas interpretaciones, nuevas concepciones, que se convierten en culturas alternativas, en proyectos políticos humanistas, en propuestas económicas desafiantes y provocativas a esa oficialidad política y cultural de dominación. Respecto a estos elementos de nuevas culturas emergentes, Gallardo (2006) escribe que:

la expresión "cultura alternativa" referida a la sensibilidad práctica de los movimientos populares, a su manera de estar en el mundo y de producirlo y apropiárselo, indica al menos tres críticas: [nos interesa citar solo la primera]

a) La de la cultura de sometimiento gestada en los procesos sociohistóricos de la conquista y colonia, y en la estructuración oligárquica de clases del capitalismo norteamericano $[\ldots]$ contra esa cultura de sometimiento, se plantea una cultura que surge desde las diversas tramas sociales de sujeción, pero como réplica y

\section{(C) $(\otimes \otimes \odot$}

La Revista Estudios es editada por la Universidad de Costa Rica y se distribuye bajo una Licencia Creative Commons Atribución-NoComercial-CompartirIgual 3.0 Costa Rica. Para más información envíe un mensaje a 


\section{Especial: Profesores de Estudios Generales Investigan}

oposición personal y social a ellas, como testimonio de resistencia y de capacidad para generar un distinto tipo de existencia y sociabilidad, y ofrecerla a otros como desafío y convocatoria. Una cultura de la creación... (pp.138-139)

Dos elementos claros y muy importantes menciona Gallardo (2006) aquí, que nos demuestra el carácter contracultural de la Revolución bolivariana: "testimonio de resistencia y de capacidad para". Si nos detenemos brevemente en estos dos aspectos, nos damos cuenta de que la resistencia y la creatividad fueron elementos propios de los grupos disidentes y transgresores. Los grupos de contracultura resistieron a los valores tradicionales y crearon nuevas formas de organización social. La Revolución bolivariana resiste y construye una cultura alternativa; resiste a las clases oligárquicas y a la vez busca la construcción de una nueva alternativa de sociedad, más inclusiva, más participativa, más humana. Estas son las razones por las cuáles quienes más apoyan masivamente las políticas de la Revolución bolivariana son los sectores populares, los más pobres y abandonados de la sociedad, que durante muchos años fueron excluidos y marginados del progreso, la justicia social y el desarrollo económico. Al contrario, quiénes más adversan estas políticas son las clases medias y altas venezolanas, la derecha, la jerarquía eclesial, los grandes medios de comunicación social y las cámaras empresariales; esta es la cultura oficial que representa la oposición a la Revolución bolivariana. Los sectores de poder venezolanos, comandados por los grandes medios de comunicación social, por las cámaras empresariales, la jerarquía eclesial y la oligarquía tradicional, ven como una amenaza a su cultura oficial, tradicional, y a su sistema político económico liberal y capitalista, la propuesta de una sociedad identitaria, alternativa, socialista, bolivariana y humanista.

Un elemento importante del proceso revolucionario bolivariano es el concepto mismo de democracia. Alejándose del concepto tradicional de democracia 


\section{Especial: Profesores de Estudios Generales Investigan}

impuesto por las oligarquías tradicionales, basado en la representación y en la división de poderes, la nueva concepción de democracia se basa en la participación popular, en la descentralización del poder, en la nacionalización de los hidrocarburos, en la justa distribución de la riqueza, la justicia social, el plebiscito, el referéndum. Todo eso va en contraposición al concepto de democracia liberal capitalista.

Esta nueva concepción de democracia es lo que hace a la Revolución bolivariana oponerse a la cultura democrática oligárquica tradicional; marca una posición de avanzada, desplazando a los valores y principios dominantes, confronta con nuevos valores a esa cultura de la dominación y se convierte así en vanguardia de las clases desposeídas. Es una democracia que integra e incorpora todo un legado histórico, político y social; asume principios y valores bolivarianos, marxistas, regionales, nacionalistas, comunistas, independentistas, cristianos, indigenistas, entre otros más; esa articulación de principios la consolida como una revolución única, particular y específica. Al igual que los movimientos contraculturales, la Revolución bolivariana, a mayor escala, va creando un nuevo ser humano, es el llamado ser bolivariano, inspirado en los valores de la revolución y practicante de ellos. Esta propuesta alternativa de democracia es un proyecto político abierto, heterogéneo e incluyente. Hacia lo anterior apunta Caponi (2001) cuando dice que

tomamos el término bolivariano como el mito o símbolo político fundador, piedra angular sobre la cual articular la construcción del proyecto de democracia no liberal incluyente. Es importante aclarar que se trata de un proyecto políticoideológico abierto y en pleno desarrollo [...] definir la democracia como bolivariana no significa remitirnos textualmente al pensamiento de Bolívar, sino más bien rescatar una visión popular de nuestra época y de nuestro país. Gramscianamente podemos afirmar que dentro de la visión del mundo del venezolano, desarticulada 


\section{Especial: Profesores de Estudios Generales Investigan}

y episódica en cuanto basada en el sentido común, conformado por estratos superpuestos de ideologías y visiones del pasado, existe un buen sentido, conciencia embriónica y todavía no bien articulada del ser bolivariano (p.90).

Ese ser bolivariano del que nos habla Caponi (2001) es una articulación del hombre nuevo del Che Guevara, del“ser cristiano de la Teología de la Liberación, del combatiente guerrillero de la revolución armada y del demócrata comprometido de la democracia popular y participativa. Es el nuevo ser humano contracultural, que actúa sabiéndose comprometido con el otro. Es el embrión que va surgiendo engendrado por el proceso revolucionario bolivariano.

La Revolución bolivariana se ubica actualmente en un contexto muy particular en América Latina. El resurgimiento de gobiernos de derecha, liberales y ultraconservadores, que promueven y defienden la propiedad privada, el libre mercado y la sumisión a las políticas tradicionales de imposición y dominación de Ios EE. UU. Este ser bolivariano se autoconstruye en un contexto de confrontación y desafío, atacado por todos los lados por el capitalismo internacional y la oposición oligárquica interna.

Los principios ideológicos de la Revolución bolivariana van contra corriente de la cultura oficial de dominación y se convierte en la vanguardia contracultural de las clases más desposeídas de la sociedad. Pero hay algo muy particular de este movimiento contracultural bolivariano, y es que el mismo, a la vez, no es un movimiento contracultural como los que tradicionalmente conocemos; se distancia de ellos en que es un movimiento más abierto, más amplio y más general, y con resultados muchos más efectivos. Debemos reconocer que los movimientos tradicionales de este tipo eran movimientos más reducidos, muy específicos y muy limitados por una serie de factores y situaciones; eran movimientos rebeldes y de confrontación que desafiaban al sistema, pero por su misma naturaleza no representaban un peligro inminente a ese poder hegemónico oficial; incluso

\section{(c) (i) (-)}

La Revista Estudios es editada por la Universidad de Costa Rica y se distribuye bajo una Licencia Creative Commons Atribución-NoComercial-CompartirIgual 3.0 Costa Rica. Para más información envíe un mensaje a revistaestudios.eeg@ucr.ac.cr. 


\section{Especial: Profesores de Estudios Generales Investigan}

aquellos que no desaparecieron o se disolvieron con el tiempo fueron cooptados por el sistema mismo. Su rebeldía fue vista, al pasar de los años, como una rebeldía que no produjo transformaciones profundas al interior de la cultura dominante. En relación con esta visión histórica de los movimientos contraculturales, el especialista en este tema, Jiménez Hernández, haciendo referencia a Britto García, nos dice que

...la contracultura profesó una serie de utopías de un marcado corte ingenuo, cuyo contenido no presentaba un peligro estratégico para la modernidad capitalista. Las consignas sobre la paz y el amor, los símbolos del hippismo, la onda de las flores y los alucinógenos, fueron, justamente, las características más publicitadas por los medios de comunicación de masas y de los que pronto el aparato de dominación cultural capitalista se apropió, en un proceso por el cual, al universalizar comercialmente un símbolo, este sufre un vaciamiento de contenidos y una inversión plena de su significado, deviniendo las contraculturas, de movimientos potencialmente transformadores e impugnadores, en decadentes subculturas de consumo. (1992, pp.119-120)

Si bien las contraculturas anteriores no tuvieron efectos políticos y transformadores como cultura alternativa dentro de la cultura oficial, sí expresaron fundamentos políticos e ideológicos y una visión de mundo, de ser humano y de sociedad alternativa. En lo que fallaron estas contraculturas fue en las tácticas y en las estrategias, en la forma y en el método que hicieran posible la consolidación de su pensamiento. Aunado a esto, la cultura hegemónica utilizó todos los medios a su alcance para frenar los movimientos contraculturales. Confirmando esta apreciación, Jiménez Hernández (1992) nos dice que "El contenido político y revolucionario de la contracultura, por el contrario, fue sistemáticamente ocultado y tergiversado por los medios de comunicación de masas, y las luchas

\section{(c) (i) (2)}

La Revista Estudios es editada por la Universidad de Costa Rica y se distribuye bajo una Licencia Creative Commons Atribución-NoComercial-CompartirIgual 3.0 Costa Rica. Para más información envíe un mensaje a 


\section{Especial: Profesores de Estudios Generales Investigan}

multitudinarias que se desarrollaron en torno a esos contenidos, fueron víctima de una represión policíaca y militar abierta y punitiva" (p.120).

Otra cosa muy distinta parece ser la Revolución bolivariana. Primero, es un movimiento muy amplio y transformador, que abarca a toda la sociedad venezolana y se extiende más allá de sus fronteras; segundo, consiste en una amenaza fehaciente a los grupos de poder político y económico oligárquicos que han usurpado con sus valores culturales tradicionales las riquezas del país; tercero, se inscribe en ideales sociohistóricos que han sido satanizados y vilipendiados por el sistema oligárquico capitalista que lo ha visto y aún lo ve como una amenaza a su egoísmo opulento y acumulativo; cuarto, consiste en el desplazamiento de la democracia representativa por una democracia participativa desde abajo y desde adentro.

\section{Ideas finales}

La Revolución bolivariana posee, expresa, manifiesta, contiene rasgos que son propios de los movimientos contraculturales. Es un movimiento de oposición que desafía, confronta, combate y amenaza a la cultura capitalista dominante y, a la vez, propone, construye, indica y recomienda una alternativa social, política, económica, humanista y contracultural distinta a esa cultura hegemónica. La Revolución bolivariana, expresión política e ideológica del socialismo del siglo XXI, lucha para que su propuesta alternativa contracultural y revolucionaria sea posible en la sociedad venezolana en particular y en las sociedades latinoamericanas en general. Es un movimiento político e ideológico que busca una sociedad más humana, más crítica, más libre, incluyente y participativa.

Tres rasgos o características distinguen este nuevo socialismo del socialismo que dominó parte de la historia humana en el siglo XX. Su nueva visión de mundo lo determina como un socialismo propio del siglo XXI, incluye dentro de su diario o

\section{(๑) $\odot \odot$}

La Revista Estudios es editada por la Universidad de Costa Rica y se distribuye bajo una Licencia Creative Commons Atribución-NoComercial-CompartirIgual 3.0 Costa Rica. Para más información envíe un mensaje a 
Especial: Profesores de Estudios Generales Investigan

plataforma ideológica lo ecológico, lo feminista y lo cristiano; tres aspectos que no se tomaban en cuenta en el que llamaremos socialismo tradicional o clásico. La Revolución bolivariana toma muy en cuenta, y muy en serio, esos tres factores sociales; los considera parte fundamental de la convivencia, realización y existencia del ser humano en sociedad, en donde todos y cada uno de los seres humanos, junto a su entorno, sean sujetos históricos de transformación y cambio.

\section{Bibliografía}

Britto García, L. (1994). El imperio contracultural: del rock a la posmodernidad.

Caracas, Venezuela: Editorial Nueva Sociedad.

Caponi, O. (2001). La democracia bolivariana desde una perspectiva gramsciana. En J. Maerk (Coord.). ¿Cómo democratizar la democracia? (pp. 85-94). México: Plaza y Valdés.

Dieterich, H. (2003). El Socialismo del Siglo XXI. El Salvador: Editorial Rumbo Revolucionario.

Dunn, J. (1986). La teoría política de occidente ante el futuro. México: Fondo de Cultura Económica.

Fukuyama, F. (1992). El fin de la historia y el último hombre. Barcelona, España: Editorial Planeta.

Gallardo, H. (2005). Siglo XXI, militar en la izquierda. San José, Costa Rica: Arlekin.

Gallardo, H. (2006). Siglo XXI producir un mundo. San José, Costa Rica: Editorama.

Golinger, E. (2006). Bush vs. Chávez: la guerra de Washington contra Venezuela. Ciudad de La Habana, Cuba: Editorial José Martí.

Harnecker, M. (2001). La izquierda latinoamericana y la construcción de alternativas. Cuba: Siglo XXI.

\section{(c) (1) 8 ()}

La Revista Estudios es editada por la Universidad de Costa Rica y se distribuye bajo una Licencia Creative Commons Atribución-NoComercial-CompartirIgual 3.0 Costa Rica. Para más información envíe un mensaje a 
Jiménez Hernández, J. (1992). Utopías y antiutopías de las contraculturas. En Reflexiones Filosóficas (pp. 107-132). San José, Costa Rica: Publicaciones de la Asociación de Profesores de Filosofía, Escuela de Estudios Generales.

Moore, S. (1989). Crítica de la democracia capitalista. México: Siglo XXI Editores. Randle, M. (1998). Resistencia civil. La ciudadanía ante las arbitrariedades de los gobiernos. Barcelona, España: Ediciones Paidós Ibérica.

Rauber, I. (2003). Movimientos sociales. Representación política. Bogotá, Colombia: Ediciones Desde Abajo.

Schnapper, D. (2004). La democracia providencial: Ensayo sobre la igualdad contemporánea ( $1^{\mathrm{a}}$ ed.). Rosario, Argentina: Homo Sapiens.

Ubieta Gómez, E. (2006). Venezuela rebelde. Solidaridad vs. Dinero. La Habana, Cuba: Ediciones Abril. 